\section{Violência e saúde como um campo interdisciplinar e de ação coletiva}

\section{Violence and bealth care as an} interdisciplinary field and an arena for collective action
Maria Cecília de Souza Minayo*

Edinilsa Ramos de Souza**

* Doutora em saúde pública, professora adjunta da Escola Nacional de Saúde Pública (Ensp), vice-presidente de Informação, Comunicação e Meio Ambiente da Fiocruz

** Pesquisadora associada da Ensp/Fiocruz. Ambas participam do Centro Latino-Americano de Estudos de Violência e Saúde Jorge Careli (Claves/Ensp/Fiocruz) Av. Brasil 4036, sala 702 Manguinhos 21040-360 Rio de Janeiro - RJ Brasil
MINAYO, M. C. de S. e SOUZA, E. R. de: 'Violência e saúde como um campo interdisciplinar e de ação coletiva'. História, Ciências, Saúde-Manguinhos, IV(3): 513-531, nov. 1997-fev. 1998.

Este artigo tenciona apresentar a complexidade da reflexão sobre violência e saúde e, ao mesmo tempo, o campo de possibilidades que a temática abre tanto para a colaboração interdisciplinar, como para a ação multiprofissional. Busca elaborar uma crítica das visões que absolutizam o sentido da violência, sem, no entanto, pretender apontar uma resposta definitiva. Adverte para o risco epistemológico e prático de reducionismo que corre o setor de saúde ao querer tratar esse fenômeno como uma epidemia e para a necessidade de colaboração intersetorial e com a sociedade civil.

É um artigo aberto, com mais perguntas que respostas, mas apresentando uma proposta interdisciplinar entre as ciências sociais, a epidemiologia e a psicologia.

PALAVRAS-CHAVE: violência e saúde, interdisciplinaridade, causas externas.

MINAYO, M. C. de S. and SOUZA, E. R. de: Violence and health care as an interdisciplinary field and an arena for collective action, História, Ciências, Saúde - Manguinhos,

IV(3): 513-531 nov. 1997-feb. 1998.

While the question of violence and bealth is a complex one, it opens the door for interdisciplinary collaboration and multi professional efforts. Altbough this article does not intend to provide any definitive responses, it does endeavor to critique vieupoints that attribute an absolute meaning to the term 'violence'. It warns that this bealth-care sector mins the epistemological and practical risk of falling into reductionism when it addresses violence as if it were an epidemic.

Furthermore, this sector needs to collaborate with other sectors and with civil society. More than offering answers, the article raises questions within the framework of an interdisciplinary approach encompassing the social sciences, epidemiology, and psychology.

KEYWORDS: violence and bealth, interdisciplinary studies, external causes. 


\section{Introdução}

E sta reflexão metodológica sobre a violência e seu impacto na saúde decorre de estudos teóricos e pesquisas empíricas desenvolvidas pelo Centro Latino-Americano de Estudos de Violência e Saúde (Claves), durante os seus oito anos de existência na Fundação Oswaldo Cruz (Fiocruz). Neste artigo, trafegamos por uma estrada de mão dupla, cotejando a realidade fenomênica com reflexões conceituais e procurando converter o produto dos estudos em temas de debate e ações de proteção à saúde. A opção por uma via que articula teoria, método e estratégias de ações se deve à especificidade do objeto 'violência', tão difícil de ser abordado pelas formas convencionais de conhecimento em razão da carga de ideologia, preconceito e senso comum que invariavelmente o acompanha. Por outro lado, os sanitaristas freqüentemente manifestam estranheza ao se depararem com um fenômeno social que causa agravos à saúde, mas não se enquadra com facilidade nos esquemas habituais das disciplinas da saúde coletiva na tradição de um ofício mais voltado para o campo das doenças e sua determinação social.

Como todos os que tentam construir conceitos e relações, apoiamo-nos nos conhecimentos desenvolvidos pela epidemiologia das 'causas externas', que já tem certa tradição em nosso país. Com uma postura aberta e crítica, estamos tentando desenhar um marco teórico-metodológico que seja útil às investigaçôes empíricas e às ações estratégicas.

\section{Violência, um conceito polissêmico e controverso}

Qualquer reflexão teórico-metodológica sobre a violência pressupõe o reconhecimento da complexidade, polissemia e controvérsia do objeto. Por isso mesmo, gera muitas teorias, todas parciais. Neste artigo, levando em conta o que acontece na prática, dizemos que a violência consiste em ações humanas de indivíduos, grupos, classes, nações que ocasionam a morte de outros seres humanos ou que afetam sua integridade física, moral, mental ou espiritual. Na verdade, só se pode falar de violências, pois se trata de uma realidade plural, diferenciada, cujas especificidades necessitam ser conhecidas.

A interpretação de sua pluricausalidade é, justamente, um dos problemas principais que o tema apresenta. Basta freqüentar as páginas dos grandes jornais que publicam debates de especialistas para se perceber a dificuldade que têm de alcançar definições consensuais. Assim, muitas são as tentativas de explicação. De um lado estão os que sustentam que a violência resulta de necessidades biológicas, psicológicas ou sociais, fundamentando-se na 
${ }^{1}$ Etologia social - do grego ethos: costume, caráter; logos: palavra - é al doutrina da conduta dos animais em seu meio natural, e se clesenvolveu entre as décadas de $1940 \mathrm{e}$ 1950. Introcluz os métodos e o enfoque da biologia no estudo da conduta humana.

Diversos autores tentam demonstrar que os seres humanos desencadeiam guerras, amotinam-se e se rebelam porque são impulsionados pelo eterno e indestrutível instinto de agressão. sociobiologia ou na etologia, teorias que subordinam a questão social às determinações da natureza. De outro, estão os que explicam a violência como fenômeno de causalidade apenas social, provocada quer pela dissolução da ordem, quer pela 'vingança' dos oprimidos, quer ainda pela fraqueza do Estado.

O primeiro grupo de teorias entende a violência como fenômeno extraclassista e a-histórico, de caráter universal, constituindo mero instrumento técnico para a reflexão sobre as realidades sociais. Nielburg (1959, p.15), por exemplo, absolutiza o papel da violência na vida social e, bem ao estilo de Hobbes, enfoca a sociedade como eterno campo de luta competitiva entre indivíduos, grupos e nações. Em sua opinião, os métodos e meios deste embate só se modificam porque a própria luta representa um fenômeno natural. Seguindo a mesma linha, Lawrence (1970, pp. 35-6) critica a busca do que chama sintomas secundários de tais ou quais atos de violência, e advoga a pesquisa de "padrões científicos únicos" aplicáveis a quaisquer fenômenos dessa natureza. $\mathrm{O}$ autor crê na possibilidade de se encontrar uma definição neutra, rigorosa, isenta de moral partidária, desde que se controlem os juízos de valor.

Essas teorias fundamentam-se na idéia de que a agressividade é uma qualidade inata da natureza humana e, portanto, os conflitos da vida social, seja qual for a etapa do desenvolvimento histórico, são de caráter "eterno e natural".

Outras teorias, igualmente fundamentadas na premissa de que a violência é natural e inevitável, substituem a idéia de processo social e histórico pelo conceito de "agressão", que provém da biologia, etologia, genética e medicina. Nestas disciplinas, a categoria 'agressividade' é entendida como parte do instinto de sobrevivência e forma natural de reação dos animais em certas condições e situaçôes, tendo, portanto, conotação de 'neutralidade' e 'naturalidade'. Ao transferirem para a análise do social, de forma linear, os conhecimentos sobre a agressividade animal, os autores que partilham a crença na "instintiva agressividade humana" pretendem subordinar, a priori, os componentes da atividade humana aos instintos biológicos. William Thorpe (1970, p. 40), por exemplo, escreve que "dificilmente existe algum aspecto da conduta dos animais que não tenha referência nos problemas da conduta humana”. Tal afirmação é, no mínimo, paradoxal. Não é o homem que se referencia na conduta do animal, mas sim o animal que se referencia no homem.

Os estudiosos que defendem tais idéias se apóiam nas descobertas da chamada etologia social, desenvolvida por Konrad Lorenz.' Para Lorenz (1979, p. 25), em certas circunstâncias, o mecanismo instintivo da agressividade dispara automaticamente nos animais, e os leva a atacar outros da mesma espécie. O autor considera essa "agressividade intraespecífica" necessária à 
preservação da espécie, tão natural e irresistível quanto, por exemplo, a fome e o instinto sexual.

Nessa mesma linha, situa-se a biologia social, que estuda a vitalidade humana e sua ligação com a sociedade. Caracteriza-se por transferir as regularidades do nível biológico ao social, e os dados da etologia para as relações humanas e, ainda, por priorizar os problemas dos indivíduos em detrimento dos da socieclade; e por reduzir as análises sociológicas às biopsicológicas. Segundo a biologia social, os genes reproduzidos de geração em geração, nos seres humanos, transmitem uma informação de sentido e conteúdo determinados, levando os indivíduos a reagir em condições concretas do ambiente de forma a garantir a sua sobrevivência.

Em outras palavras, a biologização dos fenômenos e processos sociais se fundamenta na crença de que os ritmos biológicos (muito mais lentos) e os sociais (muito mais dinâmicos) são fatalmente incompativeis. Os indivíduos seriam geneticamente incapazes de se adaptar aos ritmos precipitados e às mudanças qualitativas do desenvolvimento social e tecnológico da sociedade industrial, ou pós-industrial, alterando-se, em conseqüência, os mecanismos humanos de adaptação psíquica e psicobiológica. $O$ ser humano seria, então, por natureza, anti-social, e as questões de conflito e luta resultariam de sua tendência irrefreável e 'biológica' ao domínio dos outros. A analogia com os cenários descritos pela teoria da seleção natural é evidente, como mostra, entre outros, Edward Wilson (1977).

Outros autores tendem a reduzir os fenômenos e processos sociais à conduta individual produzida por fatores psicológicos. Segundo o sociólogo inglês Colin Wilson (1964-65, p. 27), a miséria e a desigualdade foram responsáveis pela violência social, mas, hoje, o baixo nível de consciência, de liberdade e responsabilidade acarretam um sentimento de insatisfação permanente, que se expressa em confrontação e alienação, em condutas pervertidas e violentas. "Não quero dizer que todos os assassinos são psicóticos, e sim que, para entendê-los, deve-se captar algo da psicologia do século XX."

Edward Morin (1970, pp. 46-9) também considera que nossa civilização parece haver entrado numa crise que aumenta a cada dia, provocando o reaparecimento de atavismos arcaicos e a exacerbação de soluções neuróticas a curto ou longo prazos. Na sua hipótese, pois, o problema da violência moderna não é de indole social e sim psicológica. Da mesma forma, o psicólogo alemão Mitscherlich (1971) crê que qualquer modificação nas relaçôes sociais só será possível se houver mudanças na constituição psíquica do ser humano, tendo como ponto central a reconstrução de sentimentos e emoções.

Marx (1967, p. 303), por sua vez, chamava de "segunda natureza" às características sociais do ser humano, cujo conteúdo 
estaria constituído por um substrato biológico-individual e por componentes formadores de sua imagem psíquica, a partir de certos modelos de conduta internos, inatos e/ou adquiridos. Portanto, na formação de tais modelos, reconhecia que a incidência dos fatores sociais era decisiva.

Entendemos que as descobertas da biologia, psicologia, genética e neurofisiologia são fundamentais para se obter uma compreensão sócio-filosófica do humano. Igualmente importante é conhecer os mecanismos que resultam não apenas na transformação do biológico pelo social como na afirmação do biológico como dimensão constituinte do social, sobretudo agora que correntes modernas das ciências naturais têm mostrado que a consciência humana possui potenciais praticamente ilimitados para se desenvolver e conhecer o mundo. Da mesma forma, não se pode negar que as peculiaridades individuais mediatizam as reaçôes dos seres humanos aos estímulos externos. Nada disso, porém, justifica a démarche tendenciosa de se tomar cor, raça e outros atributos biológicos como determinantes da violência.

Ao iniciar sua vida, a criança encontra um mundo de vínculos e relações já formados, com tradições, normas de direito e moral, concepções ideológicas e outros elementos configurados historicamente e de relevância bem concreta. Aí ela forma sua consciência, seu estilo de vida e de reação individual. Como disse Sartre (1980, p. 57): "Eu sou o que consegui fazer com o que fizeram de mim."

Aqui se argumenta em favor da relação dialética entre indivíduo e sociedade, e não da prioridade do primeiro sobre a segunda. Marx e Engels (1971, p. 146) exprimiram bem esse ponto de vista ao afirmarem que: "O homem desenvolverá sua verdadeira natureza no seio da sociedade e somente ali; razão pela qual devemos medir o poder de sua natureza não pelo poder do indivíduo concreto, mas pelo poder da sociedade."

É claro que as análises psicológicas da violência refletem, à sua maneira, as contradições existentes na realidade: o crescimento das tendências anti-sociais, o isolamento, o medo coletivo e individual, o estado de intolerância, a alienação dos indivíduos e a espetacularização dos dramas particulares. Seria incorreto negar o mundo subjetivo em que se baseia toda a vida social e privada. É necessário enxergar no processo de atividade vital não a supremacia de uma esfera sobre outra, mas a singular unidade dialética do natural, do individual e do social, do hereditário e do adquirido. Existe uma complementaridade dinâmica entre o biológico, o psicológico, o social e o ecológico, como tão bem compreendeu Marcel Mauss (1974) em sua teoria do fato social total, segundo a qual toda atividade vital humana põe em jogo relações sociais, culturais e emoções, e afeta tanto a constituição 
física, corpórea e biológica, quanto a consciência e o espírito humanos.

A conjunção dialética do social e do biológico no ser humano inscreve-se no seu emocional, o que significa que suas aspirações e ações são fruto, a um só tempo, de suas condições sociais de vida e de suas particularidades biológicas. O significado decisivo do fator social (aí incluídas as inter-relações subjetivas e as condições estruturais da existência) não se reduz ao papel de determinante absoluto: ele é condição necessária à formação e ao desenvolvimento da personalidade.

Um segundo conjunto não homogêneo de teorias se refere às raízes sociais da violência. Uma delas explica o fenômeno como resultante dos efeitos disruptivos dos acelerados processos de mudança social, provocados, sobretudo, pela industrialização e urbanização. Seus teóricos - principalmente Merton (1968) e Huntington (1968) - fundamentam-se em análises de transições sociais e sustentam, basicamente, a idéia de que os movimentos de industrialização provocam fortes correntes migratórias com destino às periferias dos grandes centros urbanos, onde as populações passam a viver sob condições de extrema pobreza, desorganização social, expostas a novos comportamentos e sem condições econômicas de realizarem suas aspirações.

Dessa forma, a violência encontraria clima propício para seu incremento nas grandes metrópoles, sacudidas por essas bruscas mudança. Variáveis como o tamanho das cidades, a aglomeração de pessoas, a perda de referências familiares e de raízes culturais favoreceriam a formação de subculturas periféricas, à margem das normas e leis sociais, produzindo-se as chamadas "classes perigosas". As grandes cidades não seriam, então, o foco gerador da violência, como crê o senso comum, e sim o locus privilegiado da dissociação entre aspirações culturalmente criadas e 'possíveis sociais', daí se originando a delinqüência e o crime.

Como o primeiro grupo de teorias, este tem seu componente ideológico muito claro, quer na visão nostálgica de volta ao passado presente em algumas análises sociológicas, quer nas propostas autoritárias que vêem o urbano, a favela e a periferia como locus $\mathrm{da}$ violência. Essa corrente despreza os componentes microestruturais da subjetividade na escolha dos possiveis sociais. A lógica estrutural-funcionalista, que sustenta o modelo, supõe uma sociedade homogênea e estável com normas, padrões e valores dados, eternos, esquecendo a natureza sócio-histórica e a origem de classes das definições sociais. É como se o movimento de mudanças exercesse uma força de atração sobre os atores sociais, arrastando-os para condutas criminosas e violentas. Migração interna, favelização, condições precárias de vida, desemprego, acesso reduzido à escolaridade seriam geradores 
de comportamentos desviantes. Ao reduzir violência a crime e delinqüência, e ao encarar como "criminosa potencial" a população imigrante e pobre das classes trabalhadoras, os seguidores da corrente que enxerga a transição como portadora de violência não levam em conta a violência estrutural, a violência do Estado e a cultural, que quase sempre aparecem naturalizadas.

Um terceiro grupo de teorias tende a compreender os processos e as condutas violentas como estratégias de sobrevivência das camadas populares vitimadas pelas contradiçôes gritantes do capitalismo no país. As desigualdades sociais, o contraste brutal entre opulência e indigência, as poucas oportunidades de emprego, de ascensão social e remuneração condignas levariam os pobres a se rebelar e a tentar recuperar o excedente de que foram expropriados. Tais idéias inspiram-se basicamente em Sorel (1970), o primeiro teórico da explicação da violência como revolta dos despossuídos, e em Engels (1974), que situa o fenômeno da delinqüência no início da industrialização da Inglaterra como nível elementar da luta de classes. Pires (1986), Oliven $(1983,1982)$ e Cerqueira (1987) são, entre nós, alguns dos representantes dessa corrente. Ela retém uma visão exterior da violência, como força instrumental de reposição da justiça, e deixa de lado outros aspectos da violência social e cultural que têm raízes estruturais profundas e internalizadas nos sujeitos, e que atingem a todos nós, independentemente de classe, cor, raça, sexo ou idade.

Hegel (1969, pp. 299-336) foi o primeiro filósofo a integrar a violência não só à racionalidade da história das sociedades, como à origem mesma da consciência. Na análise da relação dialética entre senhor e servo, define a violência, primeiro, como processo de negação do "outro" pelo "eu". Mas essa negação não é suficiente do ponto de vista da realização social. O "eu" precisa que o "outro" exista e que o reconheça, e então a luta pela vida se transforma em luta pelo reconhecimento. Esse é o aspecto positivo das relações sociais que Freud (1974, p. 311), embora pessimista em relação ao ser humano, constatava na correspondência com Einstein: "Tudo que estimula o crescimento da civilização trabalha simultaneamente contra a guerra." Esse é também o ponto de vista adotado por Habermas (1980, p. 100) ao comentar Hannah Arendt: "As confrontações estratégicas em torno do poder político nem produziram e nem preservaram as instituições nas quais esse poder está enraizado. As instituições políticas não vivem da violência mas do reconhecimento" (reconhecer significa conhecer o que já houve na história, atualizado nas presenças).

Em resumo, cremos que não são apenas os problemas de natureza econômica, como a pobreza, que explicam a violência social, embora saibamos que eles são fruto, são causa e efeito e, ainda, elemento fundamental de uma violência maior que é o 
próprio modo organizativo-cultural de determinado povo. Ao escolher os que "são" e os que "não são" a partir das leis de propriedade, a sociedade revela sua violência fundamental, como na dialética hegeliana do servo e do senhor.

O quarto grupo de teorias explica a violência e o crescimento dos índices de criminalidade no país, pela falta de autoridade do Estado, entendendo esta como poder repressivo e dissuasivo dos aparatos jurídicos e policiais. Tal concepção tende a omitir o papel da violência como importante instrumento de domínio econômico e político das classes dominantes. Veicula a crença num Estado neutro, árbitro dos conflitos e mantenedor da ordem em benefício de todos, à margem da questão das classes, dos interesses econômicos e políticos, Estado meramente funcional em relação ao bem-estar social.

Os adeptos da força repressiva do Estado, tergiversando sobre as complexas causas da violência, reduzem sua concepção desse fenômeno à delinqüência e tendem a interpretá-la como fruto da conduta patológica dos indivíduos. Ao mesmo tempo, absolutizam o papel autoritário do Estado no desenvolvimento sócio-econômico das sociedades. As idéias desses intelectuais combinam com o senso comum, que advoga a força repressiva como condição de "ordem e progresso". Entre nós, Campos Coelho (1987) representa essa visão da delinqüência como fruto anômalo que se desenvolve à sombra da conivência e apatia das autoridades e dos aparelhos repressivos.

\section{Violência e saúde como objeto de investigação e ação}

A violência é exercida, sobretudo, enquanto processo social, portanto, não é objeto específico da área da saúde. Mas, além de atender às vítimas da violência social, a área tem a função de elaborar estratégias de prevenção, de modo a promover a saúde. Logo, a violência não é objeto restrito e específico da área da saúde, mas está intrinsecamente ligado a ela, na medida em que este setor participa do conjunto das questões e relações da sociedade. Sua função tradicional tem sido cuidar dos agravos físicos e emocionais gerados pelos conflitos sociais, e hoje busca ultrapassar seu papel apenas curativo, definindo medidas preventivas destes agravos e de promoção à saúde, em seu conceito ampliado de bem-estar individual e coletivo.

Diz Agudelo (1990, p. 1) que "a violência afeta a saúde porque ela representa um risco maior para a realização do processo vital humano: ameaça a vida, altera a saúde, produz enfermidade e provoca a morte como realidade ou como possibilidade próxima".

E a Organização Pan-Americana de Saúde (OPAS), em seu documento sobre o tema (1995, 1993), declara que "a violência, 
pelo número de vítimas e a magnitude de seqüelas emocionais que produz, adquiriu um caráter endêmico e se converteu num problema de saúde pública em vários países. ... O setor de saúde constitui a encruzilhada para onde confluem todos os corolários da violência, pela pressão que exercem suas vítimas sobre os serviços de urgência, de atenção especializada, de reabilitação física, psicológica e de assistência social."

O Brasil é um desses países onde a violência exerce impacto significativo sobre o campo da saúde (Minayo, 1994). Desde a década de 1960 , o quadro de mortalidade geral revela a transição das doenças infecto-parasitárias para a violência como fenômeno relevante, acompanhando o processo de urbanização. O ponto de inflexão situa-se na década de 1980 , que apresentou crescimento de cerca de $29 \%$ na proporção de mortes violentas, passando estas a constituir a segunda causa no obituário geral, abaixo, apenas, das doenças cardiovasculares. Os acidentes de trânsito e os homicídios respondem por mais da metade das mortes por violência, sendo baixa a incidência de outros eventos (suicídios e demais acidentes) que compõem, com os dois primeiros, a categoria Causas Externas segundo a Classificação Internacional de Doenças (CID): E-800 a E-999 na 9"1 revisão e V01 a Y98 na 10! revisão (Souza, 1994; Mello Jorge, 1994).

A morbidade por violência é difícil de ser mensurada, seja pela escassez de dados, seja pela imprecisão das informações geradas através dos boletins de ocorrências policiais, seja pela pouca visibilidade que têm determinados tipos de agravos, ou ainda pela multiplicidade de fatores que envolvem atos violentos. Muitos exemplos poderiam ser citados para se estimar a ampliação enorme da morbidade em relação à mortalidade. Mello Jorge (1988) cita estudos de Wheatley: para cada morte atribuível a acidente, duzentos a quatrocentos casos de lesões não-mortais geram seqüelas e incapacidades prematuras.

Porém, o problema não se reduz às lesões físicas e alcança nível incomensurável quando se pensa nas relações e conexôes criadas como efeito-causa e causa-efeito. O medo é apenas uma das manifestações da vivência da violência, sobretudo hoje, nas grandes regiôes metropolitanas, onde se concentram $75 \%$ cle todas as mortes por essa causa (Minayo e Souza, 1993, p. 75).

Se o fenômeno da violência, como diz Engels (1972, p. 27), é produto da história - esta "é como a mais cruel das deusas que arrasta sua carroça triunfal sobre montões de cadáveres" -, não se pode deixar de reconhecer que os processos violentos inibem, modificam e enfraquecem tanto a qualidade como a capacidade de vida. Vários estudiosos da atualidade observam que se torna cada vez mais necessária uma epidemiologia da violência, inclusive uma epidemiologia dos problemas psiquiátricos gerados por ela. 
É no âmbito dessas questões que trabalhamos o objeto 'violência e seu impacto na saúde', articulando saberes de várias disciplinas, contribuições de vários campos profissionais, com a certeza de que apenas uma abordagem intersetorial e interdisciplinar consegue abranger a problemática em questão.

Examinaremos três campos que podem fornecer essa colaboração à saúde pública.

Das ciências sociais retiramos os seguintes balizamentos.

A violência é um fenômeno histórico, quantitativa e qualitativamente, seja qual for o ângulo pelo qual o examinemos (conteúdo, estrutura, tipos e formas de manifestação). Só pode ser entendida nos marcos de relações sócio-econômicas, políticas e culturais específicas, cabendo diferenciá-la, no tempo e no espaço, e por tipos de autor, vítima, local e tecnologia, como fazem Burke (1995), Pinheiro (1982) e Farjado (1988) em seus trabalhos.

Toda violência social tem, até certo ponto, caráter revelador de estruturas de dominação (de classes, grupos, indivíduos, etnias, faixas etárias, gênero, nações), e surge como expressão de contradições entre os que querem manter privilégios e os que se rebelam contra a opressão. Até a delinqüência, ou principalmente a delinqüência, pode ser interpretada à luz dessas relações sociais conflituosas. As desigualdades sociais, a expropriação econômicosocial e cultural são ingredientes que importa compreender como base da criminalidade, como mostram os estudos de Adorno (1989) e Vethencourt (1990). A desvalorização da vida e das normas convencionais, das instituições, dos valores morais e religiosos, o culto à força e ao machismo, a busca do prazer e do consumo imediato estão hoje na base dos códigos paralelos das gangues e 'falanges' que amedrontam nossos centros urbanos.

As ciências sociais nos estimulam a complexificar os processos e eventos a serem compreendidos e, ao mesmo tempo, nos aproximam empiricamente deles. É preciso obedecer a algumas orientações normativas, como distinguir a violência das classes e grupos dominantes daquela exercida pelos que resistem. Por outro lado, entender o caráter relacional sempre presente nos eventos violentos, que faz de todos nós, em algum momento ou situação, ora vítimas ora algozes. Investigar tanto as formas mais atrozes e condenáveis para a opinião pública como situações não menos escandalosas, mas que são naturalizadas pela cultura, protegidas por ideologias e/ou instituições aparentemente respeitáveis, como a família, a escola, as empresas e o Estado. Prescrevem ainda as ciências sociais a tarefa de relacionar a violência dos indivíduos e pequenos grupos com a do Estado e da ordem estabelecida, buscando sempre estabelecer redes, como propõem da Matta (1982), Domenach (1981) e Boulding (1981). 
As ciências sociais nos chamam ainda a atenção para os aspectos culturais concernentes tanto à modelagem da consciência, dos usos e costumes atualizados no cotidiano como à 'naturalização' da violência e à criação da ideologia que repele ou justifica o limite da tolerância social. Tais aspectos são analisados por Burke (1995); Cruz Neto e Minayo (1995); Oliven (1983) e Chesnais (1981).

Em último lugar, as ciências sociais nos indicam diretrizes metodológicas. Se os objetos da violência e saúde são sujeitos em relações sócio-históricas, é necessário fugir das explicações ahistóricas, metafísicas e fatalistas, fora das situações onde acontecem. É fundamental desvendar e explicitar o caráter de dominação das instituições coercitivas ou de persuasão, apresentadas como instrumentos técnicos, acima da realidade social. É preciso, ainda, compreender a violência em sua especificidade, no sentido de que o 'caso' é complexo e contém, dialeticamente, a possibilidade de articular a forma abstrata com a realidade concreta, quantitativa ou qualitativamente, individual e coletivamente. Tais caminhos do método têm sido apresentados por Denisov (1986), Domenach (1981) e Minayo (1990).

Do campo próprio da saúde coletiva, é a epidemiologia que mais contribuições tem oferecido aos estudos da violência.

Conforme assinala Weisberg (1995), foi a partir da década de 1970 (pós-guerra do Vietnã) que um grupo de sanitaristas começou a se introduzir nos estudos sobre a violência ao estudar os anos potenciais de vida perdidos por várias causas, inclusive 'causas externas', observando, então, a alta proporção de jovens ceifados precocemente. Nos Estados Unidos assim como no Canadá e depois em vários países da América Latina, os epidemiologistas passaram a se preocupar com a prevenção, através da descrição dos grupos e fatores de risco e da busca de intervenções sociais. Weisberg observa que a abordagem da saúde contrasta com a da polícia e justiça criminal porque, enquanto para a primeira, o impacto incide sobre a vítima, para a justiça, o alvo é o agressor. Na saúde busca-se o bem-estar; na justiça, o castigo; a perspectiva criminal é reativa, enquanto a da saúde é propositiva; e, por fim, os agentes da justiça são policiais, juízes e promotores, enquanto do outro lado está a equipe de saúde.

Ao trabalhar com séries históricas, a epidemiologia tem permitido relativizar a magnitude dos dados e a tendência dos mesmos, desfazendo crenças da opinião pública, como a de que a violência tem maior impacto na atualidade e de que se trata de um fenômeno sempre crescente e sem solução. Ao atuar com variáveis de sexo, faixa etária, cor, espaço geográfico, condições sociais e econômicas, os estudos epidemiológicos buscam alcançar maior sensibilidade, precisão e especificidade na detecção e no diagnóstico dos casos (formas de incidência e prevalência). 
2 Maria Helena de Mello Jorge tem mais de vinte anos de estudos sobre o tema e vários artigos publicados, alguns citaclos aqui. Prestou assessoria ao Ministério da Saúde, a secretarias e a movimentos civis e de cidaclãos. Edinilsa Ramos de Souza também trabalha há dez anos em epidemiologia, tendo desenvolvido estudos sobre a mortalidade por violência e atividacles de reflexão e ação no âmbito dos serviços de saúde. Ver, sobretudo, sua tese de doutorado (1995). Simone Gonçalves de Assis é outra autora engajada no esforço de articular epidemiologia e outras áreas do conhecimento, especialmente nos estudos sobre morbidade. Ver também sua tese de doutorado (1995).
Buscam também identificar fatores de risco e grupos vulneráveis. Possibilitam, ainda, a desmistificação de análises acadêmicas e mitos da opinião pública sobre o que se costuma chamar 'classes perigosas' ou 'criminosos preferenciais'. Hoje, no Brasil, os vários estudos de Mello Jorge; Souza (1995), e Assis (1995) são excelentes exemplos de trabalhos de cunho epidemiológico com inequívoca contribuição social. ${ }^{2}$

É indispensável observar, porém, que, apesar do muito que já se fez no âmbito da saúde coletiva, a epidemiologia não pode ser considerada substituta de outras formas de abordagem teórica e prática, como argumenta Weisberg (1995). Elegê-la como ciência suficiente para explicar a violência significaria desconhecer as causas de ordem estrutural, cultural e conjuntural que agregam complexos fatores e elementos e que não podem ser erradicados como uma doença. Em vários países, inclusive no Brasil, a violência não pode ser considerada uma epidemia passível de ser tratada pelos métodos tradicionais da epidemiologia geral e de serviços. Como já analisamos, a complexidade do fenômeno exige abordagem ao mesmo tempo social, psicológica e epidemiológica, levando em conta, inclusive, os aspectos biológicos. E quanto mais o fenômeno se agrava, mais imperiosa é a necessidade de se trabalhar com várias disciplinas científicas e vários campos profissionais relevantes.

Os tempos estruturais, os entranhamentos culturais, as discriminações, as desigualdades extremas, a falta de oportunidade de trabalho, a escassa cidadania são questões muito profundas que transcendem as práticas específicas da área de saúde, ainda que tenha de levá-las em conta em sua ação. Apesar desses questionamentos, é fundamental valorizar a contribuição da epidemiologia e aprofundar a proposta de vigilância e atenção que a área pode exercer no processo de prevenção e promoção da saúde. Na vigilância à violência deve prevalecer uma orientação mais ética, voltada para a prevenção do que pode ser evitado e não apenas para a intervenção no que é tolerado (Souza, Assis e Silva, 1997). A adoção de um arcabouço teóricometodológico deste tipo permite pensar tanto a assistência integral aos casos endemicamente esperados de agravos violentos como a sua prevenção, com parâmetros explicativos mais amplos que englobam, além da ocorrência isolada e do risco associado ao comportamento individual, fatores de risco relacionados ao próprio ambiente, com as especificidades inerentes aos processos violentos particulares.

Mesmo que a epidemiologia fosse equivocadamente assumida como única abordagem para o entendimento da violência, certas questões permaneceriam não resolvidas por ela. Por exemplo, a dificuldade de identificar os casos nos quais a violência não imprime 
marcas físicas, como na negligência, no abandono e na violência psicológica e em outras formas de maus-tratos historicamente dependentes do saber da clínica médica. A identificação dos fatores de risco envolvidos na rede dos processos é outra questão que desnuda a dificuldade da epidemiologia de lidar com a violência. Os modelos teóricos propostos para explicar as causas dela precisam identificar a hierarquia, a força e a forma como atuam os diferentes fatores da rede causal, o que constitui um desafio ainda não superado.

A terceira disciplina relevante para o tema é a psicologia, pois, em última instância, é no indivíduo, em sua complexa totalidade, que a violência se concretiza enquanto agressão e/ou vitimação. Como já dissemos, ela está relacionada não apenas com os bens das pessoas e com seu corpo, mas com o psiquismo. Afeta o ego corpóreo e o eu psíquico. Por isso, é necessário integrar às análises da violência a psicologia social, disciplina que trabalha com conceitos importantes como processo de identificação, grupos de referências, características de personalidade, relação entre frustração-agressão e diferenciação entre agressividade e violência. Não obstante, autores como Jurandir Freire Costa (1986) constatam a dificuldade que a área psi tem de se aproximar teoricamente do fenômeno da violência. Ao refletir sobre o tema, Jurandir utiliza mais a sociologia e, sobretudo, a antropologia, do que as teorias psicanalíicas.

O trabalho de Vethencourt (1990) é um marco para se entender a contribuição da psicologia. Contrapondo-se às explicações psicogenéticas propostas para o comportamento dos jovens pobres e delinqüentes da América Latina, o autor desmistifica as raízes individuais da violência e utiliza os conceitos de violência vingativa, expansiva e egocêntrica para analisar a situação dos rapazes pobres da Venezuela que ingressaram na delinqüência. Enxerga aí um fenômeno de regressão de conduta delitiva tendendo para a violência egocêntrica. Vethencourt observa que esses indivíduos jamais, ou muito dificilmente, teriam se tornado delinqüentes se não fossem as condições de pobreza - inclusive psíquica - e violência extremas nas quais estruturam suas personalidades, com a conseqüente ausência de expectativas de realização de suas vidas dentro das normas vigentes. Situa como numa gradação: a) o estado de desestruturação sutil da personalidade; b) a desorganização do comportamento em relação aos valores socialmente aceitos; c) a reativação dos núcleos de violência sádica e ira vingativa; d) a eclosão de impulsos agressivos como reação para não cair no adoecimento; e) a perda do autocontrole pela estigmatização; e (f) o recrudescimento da raiva que se orienta contra os outros e contra o próprio grupo.

Percebendo no comportamento dos jovens delinqüentes a regressão da violência política para a violência delinqüencial individual, Vethencourt considera essa involução o pior de todos 
os males que podem ocorrer a uma nação, já que se cria uma maneira de viver na violência crônica, sem saída aparente, por efeito do apodrecimento das energias políticas do povo, refletindose, tal estado de coisas, nos comportamento individuais.

Aos argumentos de Vethencourt podemos acrescentar que o ato de delinqüir não é privilégio do jovem das camadas pobres da sociedade. Cada vez mais observamos o crescimento da participação de jovens das classes média e alta na prática de crimes e atividades ilícitas.

Por outro lado, seria o caso de nos perguntarmos se é adequado o argumento de que os jovens das classes populares desprezam os valores vigentes na sociedade. Ora, se vivem num estado de violência crônica, como afirma Vethencourt, a divergência detectada nos valores e normas de conduta é falsa. Na verdade, os valores destes jovens são perfeitamente condizentes com as experiências que vivem. Divergem apenas dos valores inculcados pelo status quo. Talvez por esta via possamos explicar a marca registrada, aquela espécie de 'carimbo' que se encontra nas condições sociais e psíquicas dos jovens infratores que lotam as instituições de reclusão do sistema judiciário.

Em seus estudos empíricos, Vethencourt mostra que a produção de subjetividades tão homogeneamente criminógenas é explicada menos por mecanismos intrapsíquicos, como opção e necessidade individual, do que por causas que levam uma sociedade a produzir delinqüentes em série.

Estudos realizados com criminosos apontam como características psíquicas destes a predominância de um ego frágil, pouco integrado, com estruturas que não se desenvolveram plenamente e que permanecem regidas por pulsões parciais e arcaicas (Guerra, 1990). São também egos que se desenvolveram em meios familiares, marcados, com freqüência, por ausência ou repetidas substituiçôes da figura masculina, e submetidos a toda sorte de necessidades materiais e/ou afetivas.

Vê-se, assim, como é importante identificar e compreender, através da psicologia da criminalidade, quais os mecanismos psíquicos envolvidos - os gerais e os específicos aos sujeitos - nos diferentes contextos social e familiar e nos diferentes tipos de delito.

Como unidade dialética, o ser humano sintetiza em seus componentes psíquicos e emocionais as representações que elabora do mundo, das relações nele estabelecidas e de si mesmo, enquanto ser corpóreo e sujeito social. Só considerando a subjetividade, podemos compreender por que em uma mesma família um membro opta por comportamentos violentos e outro não. É desse ponto de vista subjetivo que Gilligan (1996) busca também compreender o comportamento de pessoas que preferem ser reconhecidas por atos violentos a não terem reconhecimento algum. 
No final da década de 1960, o francês Guy Debord (1997) denominou de "sociedade do espetáculo" e, na década seguinte, o norte-americano Lasch (1987) chamou de "cultura do narcisismo" os novos tipos de sociabilidade que vinham sendo tecidos nas sociedades pós-modernas.

Entre nós, Costa (1986) defende o pensamento de Lasch, articulando a violência às vivências narcísicas e à conseqüente constituição de miragens do ego. Segundo este autor, para a cultura (social) da violência há um correlato individual, a cultura narcísica. Nesta, a formação da imagem egóica, submetida aos efeitos de uma violência externa, provoca uma reclusão narcísica, levando ao desenvolvimento de condutas dissolventes do convívio e da sociabilidade. A ausência de ideais contribui para fazer emergir miragens do ego, próprias da dinâmica do narcisismo, destinadas, sobretudo, a assegurar a autopreservação, a qualquer preço.

Inseridos numa cultura de violência, os jovens estruturam um eu que permanece fixado em etapas anteriores do desenvolvimento psíquico, cujo funcionamento é regido pelo princípio do prazer. Trata-se, segundo Bush (1992), de um eu narcisista, investido de pulsões parciais, que, para lidar com a angústia e a ameaça internas, precisa projetá-las no outro - o externo, o que está fora - invertendo os papéis e transformando o agredido em agressor.

Birman (1997) tenta costurar os conceitos de "sociedade do espetáculo" e "cultura do narcisismo". Nas sociedades atuais, afirma, a sociabilidade resulta da exaltação do eu e da estetização da existência realizadas pelos indivíduos. O sujeito passa a ser dominado pela preocupação com a performance, e seus gestos permancem voltados para a sedução do outro, que é apenas objeto predatório para o gozo e enaltecimento do eu. No universo do espetáculo realiza-se, então, a captura narcísica do outro. Ser e parecer se identificam no discurso narcísico, subvertendo o verdadeiro e o falso, o original e o simulacro. A sociabilidade é antiplatônica, pois o sujeito perde a interioridade à medida que ganha exterioridade, numa cultura em que se exalta desmesuradamente o eu.

Estas reflexões são apenas fragmentos de teorias psicológicas que demonstram a necessidade de serem aprofundadas. Ou seja, entre o eu corpóreo da biologia e da cultura e o eu social do universo sociológico existe a mediação dos desejos, das emoções e das pulsões. A contribuição das disciplinas psi é urgente e fundamental. 


\section{Conclusão: urgência de interdisciplinaridade, multiprofissionalidade e ação pública}

Procuramos fazer uma leitura crítica dos termos que orbitam em nosso campo de estudo: os conceitos de violência e saúde enquanto processos, a classificação de causas externas, o conceito biopsíquico de agressividade e outros foram examinados à luz da preocupação de se obter complementaridade, transitividade ou compatibilidade na construção da temática que fornece o título ao artigo. Certamente, trata-se de um esforço incompleto que se tornará mais frutuoso no decurso de investigações e práticas.

Por não possuir uma fundamentação natural, nem transcendental ou infalível, o entendimento desse tema tão próximo de nós, tão fugidio e desafiante requer sempre a exposição dos estudos e descobertas que foram alcançados e postos em prática. Requer, ainda, busca de coerência de linguagem entre disciplinas e teorias distintas e entre métodos quantitativos e qualitativos, exploratórios, descritivos e analíticos.

Nada supera, porém, o esforço de articulação com a vida, identificada aqui como o mundo da cultura, dos direitos humanos, da lei, dos movimentos sociais e dos serviços sociais e de atenção à saúde. Neste mundo da vida, buscamos os elementos para compreender e superar.

Sublinhamos que a reflexão sobre a interdisciplinaridade e multiprofissionalidade no campo da práxis violência e saúde não é uma imposição externa e sim exigência epistemológica intrínseca e essencial. Sem pretender esgotar esta reflexão metodológica, julgamos importante ressaltar que o princípio da cooperação é central e deve prevalecer sobre a hierarquia das clisciplinas, a competição institucional e a oposição entre teoria e prática. Ao se lidar com o tema da violência, só se alcançará legitimidade através da argumentação num coro polifônico e dialógico.

O presente texto deve ser relativizado, já que se apóia em preocupaçôes acadêmicas. A violência, antes de ser um problema intelectual, é uma questão da práxis sócio-política. Desse ponto de vista, requer a busca social das condições que a engendram. O contrário da violência não é a não-violência, é a cidadania e a valorização da vida humana em geral e de cada indivíduo no contexto de seu grupo. Jean Claude Chesnais, já citado neste trabalho, ao estudar dois séculos de violência na Europa, mostra que as variáveis fundamentais da significativa diminuição da criminalidade, da delinqüência e das mortes violentas no berço do Ocidente foram as lutas dos trabalhadores por melhores condições de vida e maiores direitos associadas à institucionalização da educação formal e do Estado democrático.

É verdade que muito se poderia discutir ainda sobre outras disciplinas fundamentais que abordam a violência, como a criminologia 
e o direito criminal, por exemplo. Não temos fôlego para tanto. Limitamo-nos à tentativa de mostrar que caminhos podem ser traçados e trilhados a partir da colaboração necessária entre os três campos indicados.

Seja como for, qualquer esforço interdisciplinar só tem sentido no terreno prático, onde os profissionais de saúde possam somar colaborações interinstitucionais e intersetoriais e buscar apoio da sociedade civil.

Num âmbito mais restrito, é fundamental o diálogo entre a saúde pública e os serviços médicos, clínicos e de emergência. No que diz respeito às relações da saúde com outros setores, as ações coletivas demandam entendimento com a educação, os serviços sociais, a justiça, a segurança pública, o ministério público, o poder legislativo e, sempre, com os movimentos sociais.

\section{REFERÊNCIAS BIBLIOGRAFICAS}

Adorno, $\mathrm{S}$. 1989

Agudelo, S. F. 1990

Assis, S. G. de 1995

Birman, Joel 17.6.1997

Boulding, $E$. 1981

Burke, $P$. 1995

Bush, C. R. S. 1992

Cerqueira, $\mathbf{G}$. 1987

Chesnais, J. C. 1981

Coelho, E. C. 1987

Costa, J. F. 1986

Cruz Neto, O. e Minayo, M. C. de S. 1995
Raízes politico-ideológicas da violência. São Paulo, NEV.

'La violencia: un problema de salud pública que se agrava en la región'. Boletin Epidemiologico de la OPS, $\mathrm{n}^{2} 11$, pp. 1-7.

Trajetória sócio-epidemiológica da violência contra a criança e o adolescente. Tese de doutoramento, Rio de Janeiro, Ensp/Fiocruz.

'As alquimias do mal-estar da atualidade'.

Jornal do Brasil, p. 9.

'Las mujeres y la violencia social'. Em A. Joxe (org.), La violencia y sus causas. Paris, Unesco, pp. 265-79.

'Violência social e civilização'.

Braudel Papers, n². 12, pp. 1-8.

'A estruturação do eu e o fenômeno dos meninos de rua.

A violência no jovem de hoje. Por quê?'. Boletim Cientifico (edição especial), Sociedade Psicanalítica do Rio de Janeiro, ano XIII, n² 1, pp. 17-24

A violência na boca do povo.

Porto Alegre, Ed. Sérgio Fabris.

Histoire de la violence.

$2^{\mathrm{n}}$ ed., Paris, Pluriel.

'A criminalidade violenta urbana'.

Série Estudos, Rio de Janeiro, Iuperj.

Violência e psicanálise.

Rio de Janeiro, Graal.

Corpos e sonbos destruídos. 'Introdução'.

Rio de Janeiro, Ensp/Fiocruz. (mimeo.) 
da Matta, R. 1982

Debord, Guy 1997

Denisov, $\mathrm{V}$. 1986

Domenach, J. M. 1981

Engels, $\mathrm{F}$ 1974

Engels, F. 1972

Fajardo, E. 1988

Freud, 5. 1974

Gilligan, J. 1996

Guerra, A. G. 1990

Habermas, J. 1980

Hegel, G. F. 1969

Huntington, S. 1968

Lasch, C. 1987

Lawrence, J. 1970

Lorenz, K. 1979

Marx, K. 1967

Marx e Engels 1971

Mauss, $M$ 1974

Mello Jorge, $M . H$. 1994

Mello Jorge, M. H. 1988

Merton, R. 1968
'As raízes da violência no Brasil'. Em P. S. Pinheiro (org.), Violência brasileira. São Paulo, Brasiliense, pp. 49-54.

A sociedade do espetáculo.

Rio de Janeiro, Contraponto.

Violencia social: ideologia y política.

Moscú, Editorial Progreso.

'La violencia'. Em A. Joxe (org.), La violencia y sus causas.

Paris, Unesco, pp. 33-46.

A situação da classe trabalbadora na Inglaterra.

Lisboa, Ed. Presença.

Théorie de la violence.

Paris, Edition 10/18.

Em julgamento a violência no campo.

Rio de Janeiro, Fase/Vozes.

'Reflexões para os tempos de guerra e morte'.

Em Obras Completas de Sigmund Freud.

Rio de Janeiro, Imago, pp. 311-39.

Violence.

Nova York, G. P. Putnam's Sons.

O crime, realidade, desafio: abordagem psicodinâmica do bomicídio.

Recife, s. ed.

'O conceito de poder em Hannah Arendt'. Em Habermas.

São Paulo, Ática.

Filosofia del espiritu.

Buenos Aires, Ed. Claridad.

Political order in changing societies.

Nova York, New Heaven.

O mínimo eu: sobrevivência psiquica em tempos dificeis.

4a ed., São Paulo, Brasiliense.

'Violence'. Em Social theory and practice. Nova York, Penguin Books, vol. I, pp. 35-6.

A agressão, uma bistória natural do mal. $2^{\mathrm{a}}$ ed., Lisboa, Ed. Moraes.

Writings of the young Marx on philosophy and society. Nova York, Dobleday and Company.

La sagrada familia.

$2^{\mathfrak{a}}$ ed., Buenos Aires, Ed. Claridad.

Sociologia e antropologia.

São Paulo, Edusp, vol. 1.

'Acidentes de trânsito no Brasil: dados e tendências'.

Cadernos de Saúde Püblica, n 10, pp. 19-44. Suplemento 1.

Investigaçâo sobre mortalidade por acidente e violência na infância. Tese de livre-docência, São Paulo, FSP.

Sociologia, teoria e estrutura.

São Paulo, Mestre Jou. 
Minayo, M. C. de S. 1994

Minayo, M. C. de S. e Souza, E. R 1993

Minayo, M. C. de S. 1990

Mitscherlich, A. 1971

Morin, E. jan. 1970

Nielburg, $\mathrm{H}$. 1959

Oliven, R. G. 1983

Oliven, R. G. 1982

Opas 1995

Opas 1993

Pinheiro, P. S. 1982

Pires, C. 1986

Sartre, J. P. 1980

Sorel, G. 1970

Souza, E. R. de; Assis, S. G. de e Silva,

C.M. F.P. de 1997

Souza, E. R. de 1994

Thorpe, W. ago.-set. 1970

Vethencourt, J. L. set.-dez.1990

Weisberg, B. 1995

Wilson, $C$. $1964-65$

Wilson, E. 1977
'A violência social sob a perspectiva da saúde pública'.

Cadernos de Saúde Pública, $\mathrm{n}^{2}$ 10, pp. 7-18. Suplemento 1.

'Violência para todos'.

Cadernos de Saúde Pública, n 9, pp. 65-78.

Análise da produção intelectual brasileira sobre violência e saúde. Rio de Janeiro, Panorama Ensp.

Psicoanalysis y la agresión en grandes grupos.

Madri, Ed. Tavares.

'Risk of death. Revolution. Violence'. Solidarity,

Manila, vol. 5, $\mathrm{n}^{2} 1$, pp. 46-9.

'The behavioral violence'. Em Political violence.

Nova York, Penguin Books, p. 15.

Violência e cultura no Brasil.

Petrópolis, Vozes.

Violência e cidade.

Rio de Janeiro, Zahar.

Salud y violencia. Plan de Acción Regional.

Washington. (mimeo.)

Resolución XIX: Violencia y salud.

Washington. (mimeo.)

Violência brasileira.

São Paulo, Brasiliense.

A violência no Brasil.

$3^{a}$ ed., São Paulo, Moderna.

'Questão de método'. Em Sartre.

São Paulo, Abril. Os Pensadores.

Réflexion sur la violence.

Paris, Minuit.

'Violência no município do Rio de Janeiro: áreas de risco e tendência da mortalidade entre adolescentes de dez a 19 anos'. Revista Panam Salud Publica, vol. 1 (5), pp. 389-98.

'Homicídios no Brasil: o grande vilão da saúde pública'.

Cadernos de Saude Pública, $\mathrm{n}^{2} 10$, pp. 45-60. Suplemento 1.

Unesco Courier, p. 40.

'Psicologia da violência'.

Gaceta APUCV, ano 11, no 62, pp. 5-10.

Violence, a public bealth epidemie (to appear in the jaxfax of the National Rainbow Coalition). (mimeo.)

'Crimes of freedom and their cure'. The $2 O^{\text {b }}$ Century, vol.173, no. 1.024 .

'Human sociobiology: a preface'. Essays in buman sociobiology. Nova York, Haven Press, pp. 1-50. 